\title{
Ayak Hastalıklı Broilerde Antioksidan Metabolizma ve Kemik Dokusunda Oluşan Değişikliklerin Belirlenmesi*
}

\author{
Sefa KÖSEOĞLU ${ }^{1 a}$, Halit íMiK ${ }^{1 b \bowtie}$
}

1. Atatürk Üniversitesi, Veteriner Fakültesi, Hayvan Besleme ve Beslenme Hastalıkları Anabillim Dalı, Erzurum, TÜRKiYE. ORCID: 0000-0003-1930-4920 ${ }^{\mathrm{a}}$,0000-0003-1930-4920 b

\begin{abstract}
Geliş Tarihi/Received 03.07.2020

Kabul Tarihi/Accepted 17.08.2020

Yayın Tarihi/Published 31.12.2020

Bu makaleye atıfta bulunmak için/To cite this article:

Köseoğlu S, İmik H: Ayak Hastalıklı Broilerde Antioksidan Metabolizma ve Kemik Dokusunda Oluşan Değişikliklerin Belirlenmesi. Atatürk Üniversitesi Vet. Bil. Derg., 15(3): 216-222, 2020. DOI: 10.17094/ataunivbd.763463

Öz: Broiler yetiştiriciliğinde önemli sorunların başında ayak problemleri gelmektedir. Bu çalışmada aynı şartlarda bakım ve beslenmesi yapılan 10 adet sağlıklı (SG) ve 10 adet ayak hastalıklı (AHG) olmak üzere toplam 20 adet broiler (Ross 308) kullanıldı. Uygun ortamda kesilen hayvanlardan alınan böbrek, kalp, karaciğer, but eti ve göğüs eti dokularındaki antioksidan metabolizmayı belirlemek için süperoksit dismutaz (SOD) ve katalaz (CAT) aktiviteleri ile glutatyon (GSH) ve lipid peroksidasyon (LPO) miktarları ölçüldü. Ayak hastalıklı grubun böbrek dokusunda CAT aktivitesinin, GSH ve LPO miktarlarının arttığı tespit edildi $(P<0.05)$. Yine $A H G$ 'nin but dokusunda CAT aktivitesi ve $L P O$ miktarının arttığı $(P<0.01)$, SOD aktivitesinin ise azaldığı belirlendi $(P<0.05)$. Göğüs dokusunda ise $A H G$ 'nin SOD aktivitesi, GSH ve LPO miktarlarının arttığı $(P<0.01), C A T$ aktivitesinin ise azaldığı görüldü $(P<0.01)$. Ayak Hastalıklı Grubun kalp dokusunda CAT aktivitesi ile GSH miktarının arttığı $(P<0.01)$, SOD aktivitesinin azaldığı belirlendi $(P<0.01)$. Ayrıca $A H G$ 'nin karaciğer dokusunda SOD aktivitesi $(P<0.05)$ ile $G S H$ miktarının azaldığı $(P<0.05)$ ve LPO miktarlarının arttığı $(P<0.01)$, CAT aktivitesinin ise değişmediği görüldü $(P>0.05)$. Sonuç olarak; ayak hastalıklı hayvanların tibial-tarsal kemik dokusunun tam olarak şekillenmediği, böbrek, kalp, karaciğer, but ve göğüs eti dokularında antioksidan aktivitelerin önemli oranda değiştiği, ancak bu değişiminin enzimine ve dokusuna göre farklı olduğu tespit edildi.
\end{abstract}

Anahtar Kelimeler: Antioksidan enzim, Ayak hastalığı, Broiler.

\section{Determination of Antioxidant Metabolism and Changes in Bone Tissue in Leg Disease Broilers}

Abstract: Leg problems are one of the most important problems in broiler breeding. In this study, a total of 20 broilers (Ross 308) 10 healthy (SG) and 10 legs diseased (AHG) were used. Superoxide dismutase (SOD) and catalase (CAT) activities and glutathione (GSH) and lipid peroxidation (LPO) amounts were measured to determine the antioxidant metabolism in some tissues. The CAT activity, GSH and LPO amounts were increased in kidney tissue of the leg diseased group $(P<0.05)$. Again, it was determined that CAT activity and LPO amount increased $(P<0.01)$, and SOD activity decreased in drumsticks tissue of the AHG group $(P<0.05)$. It was observed that SOD activity, GSH and LPO amounts increased $(P<0.01)$, CAT activity decreased $(P<0.01)$ in AHG's breast tissue. It was determined that the CAT activity and amount of GSH increased $(P<0.01)$, and SOD activity decreased in the heart tissue of the AHG group $(P<0.01)$. In addition, it was observed that SOD activity $(P<0.05)$ and GSH amount decreased $(P<0.05)$ and LPO amount increased in liver tissue of AHG $(P<0.05)$. As a result; it was determined that the tibial-tarsal bone tissue of the foot-diseased animals was not fully formed, antioxidant activities were significantly changed in kidney, heart, liver, drumsticks and breast meat tissues.

Keywords: Antioxidant enzyme, Broilers, Leg disease.

\footnotetext{
Walit Imik

Atatürk Üniversitesi, Veteriner Fakültesi, Hayvan Besleme ve Beslenme Hastalıkları Anabillim Dalı, Erzurum, TÜRKiYE.

e-posta: himik@atauni.edu.tr

*Bu çalışma " Ayak Hastalıklı ve Sağlıkı Broilerlerden Alınan Karaciğer, But, Göğüs, Böbrek ve Kalp Dokularında Antioksidan Metabolizma

ve Ayak Kemik Dokusunun Histopatolojik Değişimler Yönünden İncelenmesi" isimli yüksek lisans tezinin bir bölümünden alınmıştır.
} 
GiRiş

nsan beslenmesinde protein ihtiyacının önemli bir kısmı beyaz etten karşılanmaktadır. Beyaz et üretiminde ise broiler yetiştiriciliğinin çok önemli yeri vardır. Broiler yetiştiriciliğinde genetik çalışmalar sonucunda elde edilen yeni Irklar veya hatlar sayesinde hem yetiştirme süresi kısalmış hem de yem ve diğer maliyetler kısmen azalmıştır. Ancak bu olumlu neticelerin yanında hızlı gelişen hayvanlarda başta ayak problemleri olmak üzere çeşitli sağlık sorunlarının artmasına neden olmuştur $(1,2)$. Özellikle mineral, protein ve enerji metabolizmalarında dengesizlik veya bozuklukların meydana gelmesi ile çeşitli hastalıklar oluştuğu bilinmektedir. Broiler yetiştiriciliğinde görülen ayak problemlerin oluşmasında etkili olan nedenler olarak genetik, hastalık etkenleri, çevresel, yetiştirme ve beslenme gibi birçok faktörü sıralayabiliriz (1,3-7). Ayrıca kemik dokusu kas dokusu kadar hızlı gelişme özelliğine sahip değildir. Bu nedenle hızlı gelişen Irklarda kemik dokusunun bu duruma uyum sağlayamamasını da ayak hastalıklarının oluşmasında diğer önemli etken olarak belirtebiliriz. Bu durumda ise ayak problemleri kaçınılmaz olarak ortaya çıkarak sürü içerisinde önemli kayıplara (\%15'e kadar) sebep olarak çok ciddi ekonomik kayıplara neden olmaktadır.

$\mathrm{Bu}$ çalışma ayak hastalıklı hayvanların but ve göğüs eti dokularındaki antioksidan metabolizmadaki değişimleri ortaya koymak amacıyla yapıldı. Bu nedenle but ve gögüs eti dokularında süperoksit dismutaz (SOD) ve katalaz (CAT) aktiviteleri ile glutatyon (GSH) ve lipid peroksidasyon (LPO) miktarları ölçüldü.

\section{MATERYAL ve METOT}

\section{Hayvan Materyali ve Deney Grupları}

Atatürk Üniversitesi Gıda ve Hayvancılık Uygulama ve Araştırma Merkezinde yürütülen bu çalışma yine "Atatürk Üniversitesi Rektörlüğü
Veteriner Fakültesi Bilim Etik Kurulu tarafından onaylanmıştır (Karar Sayısı: 2019/10)". Ticari broilerler (Ross 308) yetiştirildiği dönemde hayvanlar takip edilerek ayak hastalıklı hayvanlar ayrıldı. İki haftalık yaştan itibaren ortaya çıkmaya başlayan ayak hastalıklı hayvanlar farklı kafeslere alınarak yem ve suya erişimleri etkilenmeyecek şekilde beslendi. Ortalama 28 günlük yaşa ulaştıklarında 10 adet ayak hastalıklı ve 10 adet sağıklı olmak üzere toplam 20 adet ticari broiler rastgele seçilerek deney grupları ayak hastalıklı grup (AHG) ve sağlıklı broiler grup (SG) olmak üzere 2 grup şeklinde yürütüldü. Bu çalışmada kullanılan ayak hastalıklı (tibial diskondoplazi) hayvanlar klinik belirtileri 20 ve 22 günlük yaşlar arasında görülenlerden seçilmiştir.

\section{Yem ve Beslenme}

Çalışma boyunca hayvanlar düzenli olarak her gün 07:30 ve 17:00 saatlerinde günde iki kez yemlendi. Yem ve su hayvanlara ad-libitum olarak uygulandı. Hayvanlara çalışmanın 1-21. günleri arası başlangıç rasyonu, 22-28. günler arası ise büyütmebitirme rasyonu verildi. Uygulanan rasyonlar NRC (8) önerisine göre formüle edildi ve besinsel bileşimi AOAC'a (9) göre belirlendi. Araştırmada başlangıç ve büyütme-bitirme yeminin besin madde oranları metabolik enerji $12.22-13.4 \mathrm{MJ} / \mathrm{kg}$, ham protein \%22.21-19.21, lizin \%1.19-1.02, metiyonin \%0.570.52, kalsiyum \% 0,96-0.81, fosfor \%0.64-0.56, Yağ \%3.48-5.56 ve ham selüloz \%2.8-2.65 olarak hesaplandı.

\section{Doku Örneklerinin Alınması}

Ortalama 28 günlük yaşa ulaşan sağlıklı ve ayak hastalıklı broilerler arasından rastgele seçilen 10'ar adet hayvan uygun ortamda kesilerek kalp, böbrek, karaciğer, but ve göğüs eti dokularından yeterli miktarda örnekler alındı. Alınan doku örnekleri steril petri kaplarına konularak biyokimyasal analizler yapılana kadar $-80^{\circ} \mathrm{C}$ de muhafaza edildi. 


\section{Biyokimyasal Analizler}

\section{Antioksidan Parametrelerinin Tespiti}

Her bir hayvanın but ve göğüs dokularından 25 mg tartılarak alındı. Her bir analiz için tampon çözeltiden üzerine $2.5 \mathrm{ml}$ eklendi ve $1 / 100$ oranında seyreltildi. Dokuların enzim aktivitelerini belirlemek için 72 saat içerisinde doku homojenatları ve doku homojenatlarından alınan süpernatantlarda Total glutatyon düzeyi (GSH) (10), Katalaz aktivitesi (CAT) (11), Lipid peroksidasyon düzeyi (LPO) (12) ve Süperoksit dismutaz aktivitesi (SOD) (13) tespit edildi. Tüm analizlerde ölçümler oda sıcaklığında yapıldı.

\section{İstatistiksel Analiz}

Çalışmada biyokimyasal analizler sonucu elde edilen veriler SPSS (14) programı kullanılarak değerlendirme yapıldı. Gruplar arasındaki farkın belirlenmesinde student $\mathrm{t}$ testi kullanıldı. Veri sonuçları ortalama sstandart hata olarak ifade edildi. İstatistiksel anlamlılık değerlendirmeleri için $\mathrm{P}<0.05$ ve $P<0.01$ değerleri kullanıldı.

\section{BULGULAR}

\section{Histopatolojik Bulgular}

Makroskobik incelemelerde ayak hastalıklı broilerlerin ilk bakışta normal ayakta duruş pozisyonunu koruyamama, yürürken zorlanma, bir ya da iki ayağını hiç kullanamama veya tamamen yerde göğsü üzerinde yatma eğiliminde olduğu belirlendi. Daha dikkatli bakıldığında ise tibiotarsal eklemlerde kalınlaşma, şişlik ve dokunulduğunda yumuşama olduğu görüldü (Şekil 1). Kesimden sonra ise hayvanların tibiotarsal kemiğin epifiz tabakasından metafiz tabakasının içine doğru uzanan opak beyaz veya donuk beyaz denilecek renkte anormal kıkırdak tabakalarına da rastlanıldı.

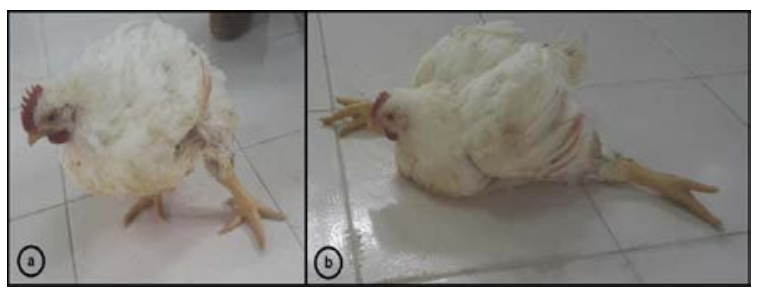

Şekil 1. Ayak hastalıklı broilerler. a: Ayakta duruş pozisyonunu koruyamama ve kalınlaşmış tibiotarsal eklemler. b: Her iki ayağını da kullanamayan ayak hastalıklı broiler.

Figure 1. Leg diseased broilers. a: Thickened tibiotarsal joints and inability to maintain standing position. b: Leg diseased broiler who cannot use both leg.

Mikroskobik incelemede ise, sağlıklı broilerlerde histopatolojik bulgulara rastlanmaz iken ayak hastalıklı broilerlerde tibiotarsal kemiklerin epifizyal büyüme tabakalarındaki belirgin bir şekilde seyreden bulgular olarak; aşırı hipertofisi artmış kondrositler ve olgunlaşmamış kondrositlerin olduğu tespit edildi. Ayrıca aynı bölgede kan damarı bakımından fakir nekrotik kondrosit yamalarının da olduğu tespit edildi (Şekil 2).

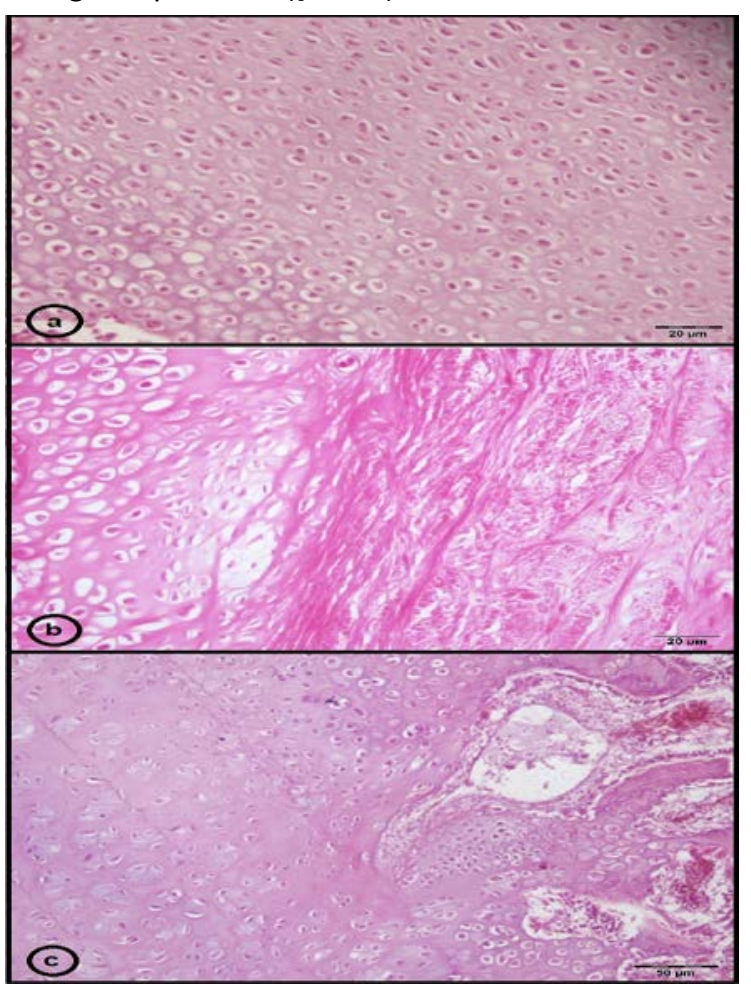

Şekil 2. Ayak hastalıklı broilerlerde histopatolojik bulgular. a: Sağlıklı broiler kondrosit görünümü. HE., Bar: $20 \mu \mathrm{m}$. b: Hastalıklı broiler kondrosit görünümü HE., Bar: $20 \mu \mathrm{m}$. c: Hastalılı broiler kondrosit görünümü HE., Bar: $50 \mu \mathrm{m}$.

Figure 2. Histopathological findings in leg diseased broilers. a: Healthy broiler chondrocyte appearance. HE., Bar: $20 \mu \mathrm{m}$. b: Diseased broiler chondrocyte appearance HE., Bar: $20 \mu \mathrm{m}$. c: Diseased broiler chondrocyte appearance HE., Bar: $50 \mu \mathrm{m}$.

Ayak hastalıklı grubun böbrek, but ve kalp dokularındaki CAT aktivitesinin sağlıklı gruba göre 
önemli miktarda arttığı $(P<0.01)$, fakat ayak hastalıklı grubun göğüs dokusunda CAT aktivitesinin sağlıklı gruba göre önemli oranda düşük olduğu belirlendi $(P<0.01)$. Karaciğer dokusunda CAT aktivitesi bakımından ayak hastalıklı ve sağlıklı gruplarda bulgularının benzer olduğu tespit edildi $(P>0.05)$ (Tablo 1).

Tablo 1. Gruplar arasındaki CAT ve SOD enzimi aktivitesinin değerleri, $(n=10)$.

Table 1. Values of CAT and SOD enzyme activity between groups, $(n=10)$.

\begin{tabular}{|c|c|c|c|}
\hline \multicolumn{4}{|c|}{ Gruplar } \\
\hline Dokular & $\begin{array}{c}\mathrm{AHG} \\
\overline{\mathrm{X}}_{ \pm \mathrm{SH}}\end{array}$ & $\begin{array}{c}S G \\
\bar{X}_{ \pm S H}\end{array}$ & Probability $(\mathrm{P})$ \\
\hline \multicolumn{4}{|c|}{ CAT Aktivitesi } \\
\hline Böbrek & $195.229 \pm 15.841$ & $66.396 \pm 4.796$ & $* *$ \\
\hline Kalp & $78.680 \pm 9.495$ & $34.721 \pm 7.589$ & $* *$ \\
\hline Karaciğer & $264.366 \pm 19.458$ & $270.660 \pm 22.370$ & ÖD \\
\hline But & $66.019 \pm 6.829$ & $49.442 \pm 8.540$ & $* *$ \\
\hline Göğüs & $36.345 \pm 3.566$ & $65.990 \pm 8.349$ & $* *$ \\
\hline \multicolumn{4}{|c|}{ SOD Aktivitesi } \\
\hline Böbrek & $14.885 \pm 0.515$ & $22.857 \pm 1.503$ & $* *$ \\
\hline Kalp & $7.179 \pm 1.295$ & $26.473 \pm 0.496$ & $* *$ \\
\hline Karaciğer & $7.150 \pm 0.899$ & $11.312 \pm 3.409$ & $*$ \\
\hline But & $21.360 \pm 3.290$ & $25.754 \pm 1.290$ & $*$ \\
\hline Göğüs & $23.545 \pm 0.379$ & $15.624 \pm 1.843$ & $* *$ \\
\hline
\end{tabular}

${ }^{*}=\mathrm{P}<0.05, * *=\mathrm{P}<0.01$, ÖD = Önemli Değil, $\mathrm{X}$ : Ortalama, SH: Standart hata

Araştırmada ayak hastalıklı hayvanların böbrek, but, kalp ve karaciğer dokularının SOD aktiviteleri sağlıklı hayvanların dokularına göre önemli oranda düştüğü $(P<0.05)$, göğüs dokusunda ise yükseldiği belirlendi $(P<0.01)$ (Tablo 1).

Araştırmada grupların böbrek, but, göğüs, kalp ve karaciğer dokularının GSH ve LPO miktarı Tablo 2 'de verildi. Ayak hastalıklı ve sağlıklı hayvanların but dokusunun GSH oranlarının benzer olduğu ( $P>0.05)$, ayak hastalıklı grubun böbrek, göğüs ve kalp dokularında GSH miktarının önemli oranda yüksek olduğu $(P<0.01)$, karaciğer dokusundaki GSH miktarının ise sağlıklı grupta önemli oranda yüksek olduğu tespit edildi $(P<0.05)$. Yapılan analizlerde grupların kalp dokularındaki LPO miktarları benzer bulunurken $(P>0.05)$, ayak hastalıklı grupların böbrek, but, göğüs ve karaciğer dokularındaki LPO miktarlarının önemli oranda yüksek olduğu belirlendi.

Tablo 2. Gruplar arasındaki GSH ve LPO enzimi miktarının değerleri, $(n=10)$.

Table 2. Values of GSH and LPO enzyme amount between groups, $(n=10)$.

\begin{tabular}{|c|c|c|c|}
\hline \multicolumn{4}{|c|}{ Gruplar } \\
\hline \multirow{2}{*}{ Dokular } & & SG & \multirow{2}{*}{ Probability (P) } \\
\hline & $\overline{\mathrm{X}} \pm \mathrm{SH}$ & $\overline{\mathrm{X}} \pm \mathrm{SH}$ & \\
\hline \multicolumn{4}{|c|}{ GSH Miktarı } \\
\hline Böbrek & $3.068 \pm 0.240$ & $2.477 \pm 0.077$ & $*$ \\
\hline Kalp & $1.936 \pm 0.173$ & $1.667 \pm 0.074$ & $* *$ \\
\hline Karaciğer & $2.639 \pm 0.161$ & $3.015 \pm 0.394$ & $*$ \\
\hline But & $2.236 \pm 0.134$ & $2.165 \pm 0.093$ & ÖD \\
\hline Göğüs & $3.044 \pm 0.220$ & $2.560 \pm 0.138$ & $* *$ \\
\hline \multicolumn{4}{|c|}{ LPO Miktarı } \\
\hline Böbrek & $21.467 \pm 1.359$ & $15.467 \pm 0.985$ & $* *$ \\
\hline Kalp & $24.853 \pm 2.242$ & $24.587 \pm 1.832$ & ÖD \\
\hline Karaciğer & $21.067 \pm 2.005$ & $16.667 \pm 1.270$ & $* *$ \\
\hline But & $43.440 \pm 1.139$ & $21.493 \pm 2.276$ & $* *$ \\
\hline Göğüs & $31.680 \pm 4.035$ & $14.080 \pm 0.694$ & $* *$ \\
\hline
\end{tabular}

${ }^{*}=\mathrm{P}<0.05, * *=\mathrm{P}<0.01$, ÖD $=$ Önemli Değil, $\mathrm{X}:$ Ortalama, $\mathrm{SH}:$ Standart hat 


\section{TARTIŞMA ve SONUÇ}

Broiler yetiştiriciliğinde hızlı gelişen ırkların geliştirilmesi ayak problemlerinin görülme oranını artırmıştır. Bunun çeşitli nedenleri olduğu bilinmektedir. Bu nedenler arasında genetik yatkınlık, enfeksiyon ile ilgili etkenler, zehirlenmeler, çevresel faktörler, stres, yetiştirme ve beslenme hastalıkları gelmektedir (1,5-7). Ayak hastalığı kemik dokusunun histolojik yapısının tam olarak gelişememesi veya hücresel bozulmaları neticesinde oluştuğu bilinmektedir. Ancak ayak hastalıklarının kalp, karaciğer, böbrek dokuları ile but ve göğüs kas dokusunun antioksidan metabolizması üzerine etkileri bilinmemektedir. Bu çalışma, ayak hastalığının kemik dokusunun histopatolojik yapısı yanında, but ve göğüs kasları, kalp, böbrek ve karaciğer dokusunun antioksidan metabolizmasına etkisini belirlemek amacıyla yapıldı.

Broiler yetiştiriciliğinde ırkların hızlı gelişmesi birçok hassasiyeti de yanında getirmiştir. Kas dokusu hızlı gelişirken, kemik dokusunun tam olarak şekillenmesi için daha uzun süreye ihtiyaç vardır. Buradan kas dokusunun ve kemik dokusunun metabolizmalarının farklı olduğu anlaşılmaktadır. Ayrıca kemik dokusunun yetiştirme esnasında oluşan herhangi bir olumsuz faktörden daha kolay etkilendiği ve ayak problemlerine neden olabileceği bilinmektedir. Bizim çalışmamızda aynı şartlarda yetiştirilen ve beslenen ayak hastalıklı ve sağlık hayvanların kemik dokularının histopatolojik yapıları incelendi. Ayak hastalıklı gruptaki hayvanların tibiotarsal kemiklerin epifizyal büyüme tabakalarında görülen aşırı hipertofisi artmış kondrositler, olgunlaşmamış kondrositlerin oluşması, ayrıca aynı bölgede kan damarı bakımından fakir nekrotik kondrosit yamalarının olması, aynı bulguların sağlıklı hayvanlarda görülmemesi literatür bilgiler ile desteklenmektedir $(5,15)$.

Ayak hastalıkları oluştuğunda özellikle Tibial diskondroplazi (TD) vakalarında bacak kemiklerinde histopatolojik olarak değişimler şekillenmektedir. Yapılan bir çalışmada tibia kemiğinde yapılan incelemede TD'li hayvan gruplarında kan damarlarının genişlediği, hücrelerde apoptozis ve daralma ile düzensiz kondrosit kolonlarının görüldüğü bildirilmiştir (16-17). Yine İmik ve ark. (5)'nın yaptığı çalışmada TD'li hayvanların tibiotarsal eklem dokusunda histopatolojik olarak dejeneratif değişiklikler, kondrositlerde hipertrofinin baskın olduğu, ürat kristalleri ve kalsifikasyonun ise olmadığını belirtmişlerdir. Bu çalışmada da hastalığın hayvanların tek bacağında veya her iki bacağında da olduğu, hayvanların ayakta duramadığı veya güçlükle durduğu görülmektedir. AHG grubundaki hayvanların kemik dokularında yapılan histopatolojik inceleme sonucunda tibiotarsal kemiğin epifiz tabakasından metafiz tabakasının içine doğru uzanan opak beyaz veya donuk beyaz denilecek renkte anormal kıkırdak tabakaları TD'li hayvanların literatürdeki makroskobik lezyonlarına uygun niteliktedir (15). Mikroskobik olarak ise tibiotarsal kemiklerin epifizyal büyüme tabakalarında kan damarından fakir bölgeler, hipertofisi artmış kondrositler, olgunlaşmamış kondrositlerin oluşuda TD'yi ilk olarak keşfeden ve anormal kıkırdak gelişimi olarak tanımlanan lezyonlara benzerlik göstermektedir $(15,17)$. Çalışmadaki histopatolojik bulgular literatürde genelde beslenme ile ilişkilendirilmiş ayak hastalıklarının etiyolojisi ile birçok noktada benzerlik gösterdiği görülmektedir.

Broiler ırkı hayvanlarda oluşan ayak hastalıklarının strese neden olduğu belirtilebilir (17). Bu çalışmada stres ile ayak hastalıklarını ilişkilendirip antioksidan metabolizma üzerine etkisi veya etiyolojisi açıklanmaya çalışıldı. Hayvan strese maruz kaldığında dokulardaki oksidan-antioksidan arasındaki denge bozularak serbest radikallerin dokularda birikmesine neden olur. Nitekim yapılan çalışmalarda broilerler strese girdiklerinde ve yürüyüş bozuklukları arttıkça kan kortikostreon konsantrasyonunun yükseldiği belirtilmiştir (18-20). Kanda kortikosteron konsantrasyonunun artması strese karşı verilen hormonal yanıt olarak kabul edilebilir (21). Hayvanlar strese maruz kaldıklarında üretilen reaktif oksijen türleri (ROS) CAT, SOD ve glutatyon peroksidaz (GSH-Px) gibi antioksidan 
enzimler tarafından uzaklaştırılmaktadır (22). Nitekim yapılan bu çalışmada ayak hastalıklı hayvanlarda oluşan stresin etkilerini azaltmada görevli antioksidan enzimlerden olan CAT aktivitesinin böbrek, but ve kalp dokularında yüksek bulunması bu bilgiler tarafından desteklenmektedir. Fakat göğüs dokusunda CAT aktivitesinin düşük bulunması muhtemelen hayvanın duruş pozisyonu ile ilgili olabileceği şeklinde yorumlanabilir. Karaciğer dokusunda CAT aktivitesinin benzer bulunması ise muhtemelen metabolik olarak uyum sağladığını göstermektedir. Çalışmada elde edilen SOD bulguları göğüs dokusu hariç ayak hastalıklı gruplarda düşük bulunması hayvanların strese metabolik olarak uyum sağlayabilmek için bu enzimi kullandığını belirtebiliriz. GSH enzimi miktarlarına baktığımız zaman karaciğer ve but dokularında benzer bulunurken, böbrek, kalp ve göğüs dokularında yüksek olması ilgi çekicidir. Bunun nedeni ise organizmada oksidadif stresin artması üzerine böbrek, kalp ve gögüs dokularındaki GSH miktarlarını uyarması sonunda yükselmiştir. Kalp dokusunun LPO seviyesi her iki grupta benzer olmasına rağmen, böbrek, karaciğer, but ve göğüs eti dokularında LPO'nun yüksek bulunması bu dokularda oksidatif stresin olduğunu göstermektedir. Mehmood ve ark. (16) broiler ırkı hayvanlarla yaptıkları çalışmalarında 7 günlük yaştaki hayvanların karaciğer dokusunda kontrol grubu ile TD'li grup arasında total antioksidan kapasite (T-AOC) seviyesi bakımından fark olmadığı ancak 10, 14 ve 18 günlük yaştaki hayvanlarda T-AOC seviyesinin TD'li grupta önemli oranda azaldığını bildirmişlerdir. Yine aynı çalışmada TD'li grupta 7, 10, 14 ve 18 günlük yaştaki broilerlerin karaciğer dokusunda SOD ve GSH-Px aktivilerinin önemli oranda azaldığını, MDA miktarının ise arttığını belirtmişlerdir. Bu sonuçlara benzer olarak yapılan bu çalışmada 28 günlük yaştaki ayak hastalıklı broilerlerin karaciğer dokusunda SOD aktivitesi ile GSH miktarının arttığı görülmüştür. Ancak LPO miktarı Mehmood ve ark. (16) yaptığı çalışmanın aksine bu çalışmada ayak hastalıklı broiler grubunda karaciğer, but ve göğüs dokularında düştüğü, kalp dokusunda benzer olduğu, fakat böbrek dokusunda yükseldiği görülmüştür. Yapılan literatür taramasında ayak hastalıklarının broilerlerde antioksidan metabolizma üzerine etkilerini gösteren çalışma sayısının oldukça kısıtlı sayıda olmasından dolayı elde edilen bulguların karşılaştırılması tam olarak yapılamamıştır.

Sonuç olarak, ayak hastalıklı hayvanların kemik dokusunu oluşturan hücrelerin tam olarak olgunlaşmadığı, deformasyonların şekillendiği tespit edildi. Ayak hastalıklı grubun antioksidan metabolizmasının sağlıklı gruba göre olumsuz etkilendiği belirlendi. Ayak hastalıklı gruptaki hayvanların but dokusu SOD aktivitesinin azaldığı, CAT aktivitesi ve LPO miktarının arttığı, GSH miktarının ise değişmeği görüldü. Göğüs dokusu incelendiğinde ayak hastalıklı grubun SOD aktivitesi, LPO ve GSH miktarlarının arttığı, CAT aktivitesinin ise azaldığı tespit edildi. Ayak hastalıklı grubun kalp dokusunda CAT aktivitesi ile GSH miktarının arttığı, SOD aktivitesinin azaldığı ve LPO miktarının ise değişmediği belirlendi. Karaciğer dokusu incelendiğinde SOD aktivitesi ve GSH miktarının azaldığı, LPO miktarının arttığı ve CAT aktivitesinin ise değişmediği görüldü. Böbrek dokusunda ise SOD aktivesi azalırken, CAT aktivesi, LPO ve GHS miktarı artığı tespit edildi. Ayak hastalıklarının oluşum mekanizmalarının tam olarak belirlenebilmesi için bu konuda yeni çalışmalara ihtiyaç olduğu belirtilebilir.

\section{Çıkar Çatışması}

Yazarlar, çıkar çatışması olmadığını beyan eder.

\section{KAYNAKLAR}

1. Crespo R., 2020. Developmental, metabolic, and other noninfectious disorders. Editor: David E. Swayne, Diseases of Poultry, p: 1286-1329, Fourteenth edition, Hoboken, NJ: WileyBlackwell, ISBN 9781119371175 (ePub) | ISBN 9781119371168, John Wiley \& Sons, Inc., 111 River Street, Hoboken, NJ 07030, USA.

2. Hartcher KM., Lum HK., 2020. Genetic selection 
of broilers and welfare consequences: a review. World Poultry Sci J, 76, 154-167.

3. Pedersen IJ., Tahamtani FM., Forkman B., Young JF., Poulsen HD., Riber, AB., 2020. Effects of environmental enrichment on health and bone characteristics of fast-growing broiler chickens. Poultry Sci, 99, 1946-1955.

4. Cao QQ., Kong AA., Tao KS., Zheng SH., Tong C., Wang XB., Huang SC., 2020. Characterization of growth performance, meat quality and serum biochemical parameters in chickens suffering from tibial dyschondroplasia. Livest Sci, 233, 103956.

5. Imik H., Terim Kapakin KA., Gümüş R., Kapakin S., Kurt A., 2012. The effect of tibial dyschondroplasia on metabolic parameters in broiler chickens. Ankara Univ Vet Fak Derg, 59, 271-277.

6. Xing R., Yang H., Wang X., Yu H., Liu S., Li P., 2020. Effects of calcium source and calcium level on growth performance, immune organ indexes, serum components, intestinal microbiota, and intestinal morphology of broiler chickens. J Appl Poultry Res, 29, 106-120.

7. Pedersen IJ., Forkman B., 2019. Improving leg health in broiler chickens: a systematic review of the effect of environmental enrichment. Anim Welfare, 28, 215-230.

8. NRC (National Research Council)., 1994. Nutrient Requirements of Poultry, 9th, Washington, DC: National Academy Press.

9. AOAC (Association of Official Analytical Chemists)., 1990. Official Methods of Analysis of the Association Official Analytical Chemists, 15th, Vol. I, Arlington, VA: AOAC.

10. Sedlak J., Lindsay RH., 1968. Estimation of total, protein-bound and nonprotein sulfhydryl groups in tissue with Ellman's reagent. Anal Biochem, 25, 192-205.

11. Aebi H., 1984. Catalase in vitro. In: Methods in enzymology. Academic Press, 121-126.

12. Ohkawa H., Ohishi N., Yagi K., 1979. Assay for lipid peroxides in animal tissues by thiobarbituric acid reaction. Anal Biochem, 95, 351-358.

13. Sun Y., Oberley LW., Li Y., 1988. A simple method for clinical assay of superoxide dismutase. Clin Chem, 34, 497-500.

14. SPSS., 2011. Statistical Packages for the Social Sciences $20^{\text {th }}$ ed. IBM: Chicago.

15. Leach JrRM., Nesheim MC., 1965. Nutritional, genetic and morphological studies of an abnormal cartilage formation in young chicks. J Nutr, 86, 236-244.

16. Mehmood K., Zhang H., Iqbal MK., Rehman MU., Li K., Huang S., Shahzad M., Nabi F., Iqbal M., Li, J., 2018. Tetramethylpyrazine mitigates toxicity and liver oxidative stress in tibial dyschondroplasia chickens. Pak Vet J, 38, 76-80.

17. Kapakin KAT., Kapakin S., Imik H., Gumus R., Eser G., 2019. The investigation of the relationship between HSP-27 release and oxidative DNA damage in broiler chickens with tibial dyschondroplasia by using histopathological and immunohistochemical methods. Braz J Poultry Sci, 21, 1-6.

18. Aydın A., 2016. Bazı fizyolojik faktörlerin etlik piliçlerin bacak aksaklıkları üzerine etkisi. KSÜ Doğa Bilimleri Dergisi, 19, 249-255.

19. Puvadolpirod S., Thaxton JP., 2000. Model of physiological stress in chickens 1 . Response parameters. Poultry Sci, 79, 363-369.

20. Weimer SL., Wideman RF., Scanes CG., Mauromoustakos A., Christensen KD., VizzierThaxton Y., 2020. Broiler stress responses to light intensity, flooring type, and leg weakness as assessed by heterophil to lymphocyte ratios, serum corticosterone, infrared thermography, and latency to lie. Poultry Sci, 99, 3301-3311.

21. Mench JA., 1992. Welfare of poultry in modern production systems. Poultry Sci, 4, 107-128.

22. Halıcı M., İmik H., Koç M., Gümüş R., 2012. Effects of $\alpha$-lipoic acid, vitamins $E$ and $C$ upon the heat stress in Japanese quails. J Anim Physiol Anim Nutr, 96, 408-415. 